\title{
Titanium dioxide nanotubes increase purinergic receptor P2Y6 expression and activate its downstream PKCa-ERK1/2 pathway in bone marrow mesenchymal stem cells under osteogenic induction
}

Chen Wang (D 532315160@qq.com)

The Second Hospital of Anhui Medical University https://orcid.org/0000-0003-0771-5079

Yanchang Liu

The Second Hospital of Anhui Medical University

\section{Xianbo Shang}

The Second Hospital of Anhui Medical University

\section{Sai Ma}

The Second Hospital of Anhui Medical University

Huihui Guo

The Second Hospital of Anhui Medical University

Yao Zhao

The Second Hospital of Anhui Medical University

Lei Liu

Suzhou Hospital of Anhui Medical University

\section{Yakun Zhu}

Fuyang Hospital of Anhui Medical University

Haoran Yu

The Second Hospital of Anhui Medical University

\section{Wendan Cheng}

The Second Hospital of Anhui Medical University

\section{Research Article}

Keywords: TiO2 nanotubes, Bone marrow mesenchymal stem cells, Purinergic receptor, PKCa-ERK1/2 signal pathway, Osteogenic differentiation

Posted Date: November 15th, 2021

DOI: https://doi.org/10.21203/rs.3.rs-1060070/v1 
License: (c) (i) This work is licensed under a Creative Commons Attribution 4.0 International License. Read Full License 


\section{Abstract \\ Background}

Titanium dioxide $\left(\mathrm{TiO}_{2}\right)$ nanotubes can improve the osseointegration of pure titanium implants, but this exact mechanism has not been fully elucidated. The purinergic receptor P2Y6 is expressed in bone marrow mesenchymal stem cells (BMSCs) and participates in the regulation of bone metabolism. However, it is unclear as to whether P2Y6 is involved in the osteogenic differentiation of BMSCs induced by $\mathrm{TiO}_{2}$ nanotubes.

\section{Methods}

$\mathrm{TiO}_{2}$ nanotubes were prepared on the surface of titanium specimens using the anodizing method. The surface morphology of the nanotubes was observed by a scanning electron microscope, and the elemental analysis was carried out by X-ray energy dispersive spectroscopy. Quantitative reverse transcriptase polymerase chain reaction and western blotting were used to detect the expression of P2Y6, markers of osteogenic differentiation, and PKCa-ERK1/2.

\section{Results}

The average inner diameter of the $\mathrm{TiO}_{2}$ nanotubes increases with an increase in voltage (voltage range of 30-90V), and the expression of $\mathrm{P} 2 \mathrm{Y} 6$ in $\mathrm{BMSCs}$ could be upregulated by $\mathrm{TiO}_{2}$ nanotubes in osteogenic culture. Inhibition of $\mathrm{P} 2 \mathrm{Y} 6$ expression partially inhibited the osteogenic effect of $\mathrm{TiO}_{2}$ nanotubes and downregulated the activity of the PKCa-ERK1/2 pathway. The osteogenic effect of $\mathrm{TiO}_{2}$ nanotubes when combined with P2Y6 agonists was more pronounced.

\section{Conclusions}

$\mathrm{TiO}_{2}$ nanotubes can promote the $\mathrm{P} 2 \mathrm{Y} 6$ expression of BMSCs during osteogenic differentiation and promote osteogenesis by activating the $\mathrm{PKCa}-\mathrm{ERK} 1 / 2$ pathway.

\section{Background}

After a prosthesis is implanted into bone tissue, the formation of good osseointegration at the contact interface is not only the basis for the long-term stability of the prosthesis but also the key to the success or failure of the implantation [1]. Although the pathophysiological mechanism of periprosthetic osseointegration is unclear, increasing evidence has shown that bone marrow mesenchymal stem cells (BMSCs) play an important role in early prosthetic osseointegration [2]. BMSCs represent cells with multidirectional differentiation potential and have the ability to differentiate into osteoblasts, adipocytes, or 
chondrocytes, all having different biological functions [3]. When BMSCs differentiate into osteoblasts, the interface around the prosthesis produces new bone tissue and grows into the surface pores of the metal implant, thus forming a strong mechanical bond between the prosthesis and the host bone [4]. When BMSCs differentiate into adipocytes, however, they tend to hinder and inhibit the formation of new bone tissue, and there is no effective mechanical bonding between bone and implants, resulting in decreased prosthesis stability and increased wear and tear [5].

However, an increasing number of studies have shown that modification of the surface morphology of the prosthesis can effectively promote the differentiation of BMSCs into osteoblasts, and accelerate the formation of new bone, thus promoting the integration of host bone and prosthesis [6, 7]. Currently, among the many kinds of prosthetic metals available, titanium (Ti) has become one of the most commonly used materials for artificial joint prostheses and bone defect implants because of its good biocompatibility, mechanical properties and chemical stability $[8,9]$. By adjusting parameters such as electrolyte composition, voltage and anodizing time using electrochemical anodizing technology, the surface of titanium can be chemically oxidized to form a unique micro-morphology [10]. Under the electron microscope, this micro-morphology shows closely arranged nanoscale long hollow tube structures, and its main component is titanium dioxide $\left(\mathrm{TiO}_{2}\right)$. The micro-morphology of $\mathrm{TiO}_{2}$ nanotubes not only helps to improve corrosion resistance, wear resistance and mechanical properties, but also the $\mathrm{TiO}_{2}$ nanotube structure of the titanium oxide layer can induce osteogenic differentiation of BMSCs and promote bone tissue formation $[7,10]$. However, the specific regulatory mechanism of osteogenic differentiation of BMSCs mediated by $\mathrm{TiO}_{2}$ nanotubes has not been fully elucidated.

As mentioned above, BMSCs can differentiate into osteoblasts and adipoblasts, and purinergic receptors all of which are involved in the dynamic regulation of this process (Jorgensen,2019; Zuccarini et al.,2021). Purinergic receptors are cell membrane receptors that can specifically bind to adenosine or purine nucleotides. The $\mathrm{P} 1$ receptors ligand is adenosine, and the ligands for $\mathrm{P} 2$ receptors are ATP and its analogues [13]. The P2 receptor family is divided into two subtypes: P2X (1-7), which are ligand-gated ion channel, and $P 2 Y(1,2,4,6,11,12,13$, and 14), which are G-protein-coupled receptors [14]. Extracellular nucleotides are released into the cell matrix as soluble factors and exert signals through specific P2 receptors on the cell surface in an autocrine or paracrine manner [12]. After activation of P2 receptors, phospholipase $\mathrm{C}(\mathrm{PLC}) / \mathrm{Ca}^{2+}$ and other related signal pathways are triggered which regulate a variety of processes involved in bone metabolism, where P2Y 6 plays an important role in osteogenesis $[15,16]$. In BMSCs from postmenopausal women, activation of UDP-sensitive P2Y6 receptors can significantly increase intracellular $\mathrm{Ca}^{2+}$ content and ALP activity and promote osteogenic differentiation $[15,16]$. In MC3T3-E1 cells, the addition of P2Y6 specific antagonists can inhibit the increase of ALP activity and other osteogenic markers [18]. However, little is known about the regulatory mechanism of P2Y6 receptors involving osteogenic differentiation of BMSCs, and the relationship between the expression of $\mathrm{TiO}_{2}$ nanotubes and $\mathrm{P} 2 \mathrm{Y} 6$ in the osteogenic differentiation of BMSCs. 
In this study, we prepared $\mathrm{TiO}_{2}$ nanotubes with different diameters and observed their surface morphologies. We found that the expression of $\mathrm{P} 2 \mathrm{Y} 6$ increased significantly after the addition of $\mathrm{TiO}_{2}$ nanotubes with different diameters to BMSCs. Next, to determine a potential key role for P2Y6 in osteogenic differentiation of BMSCs, we used P2Y6 specific inhibitors/agonists to treat BMSCs and observe the expression of their osteogenic markers. In addition, we attempted to explore the specific mechanism by which $\mathrm{TiO}_{2}$ nanotubes promote osteogenic differentiation of BMSCs through the P2Y6mediated $\mathrm{PKCa}$-ERK1/2 signaling pathway, which may provide clues as to the regulatory role of $\mathrm{TiO}_{2}$ nanotubes on osteogenic differentiation of BMSCs. These findings we help with the development of methods for guiding material design and biosafety evaluation of nano implants.

\section{Methods}

\section{(1) Preparation of $\mathrm{TiO}_{2}$ nanotubes}

A pure titanium sheet (purity $99.9 \%, 35 \mathrm{~mm} \times 35 \mathrm{~mm}, 2 \mathrm{~mm}$ thickness, Guangdong Haiyuan) was used as the substrate, and was polished with silicon carbide sandpaper, washed with acetone, then with anhydrous ethanol and deionized water in an ultrasonic cleaning machine, and dried at room temperature for $3 \mathrm{~h}$. The pretreated titanium sheet was used as the anode and a platinum sheet as the cathode, and these were immersed in an electrolyte solution of $0.15 \mathrm{M} \mathrm{NH}_{4} \mathrm{~F}$ and $90 \%$ ethylene glycol. The oxidation was carried out at $30,50,70$, and $90 \mathrm{~V}$ for $1 \mathrm{~h}$. After anodizing, each sample was rinsed with deionized water and sterilized in a $120^{\circ} \mathrm{C}$ high pressure sterilizer for $1 \mathrm{~h}$.

\section{(2) Surface morphology of the nanotubes}

The samples prepared at different voltages were washed with ethanol and deionized water and then dried at room temperature. Scanning electron microscopy (SEM, HitachiSU8010, Tokyo, Japan) was used to observe the surface structure of the samples and the average inner diameter of nanotubes was measure. At the same time, the elemental composition of the nanotubes was analyzed by $\mathrm{X}$-ray energy spectrum analysis (EDS, PHI710, Japan) and three different regions from each sample was selected and measurement three times.

\section{(3) Cell culture and treatment}

Primary rat BMSCs (purchased from Procell Life Science \& Technology Co., Ltd., China) were cultured in a-MEM medium (Gibco, USA) containing 10\% fetal bovine serum(FBS) (Gibco, USA) and 1\% penicillin/streptomycin (Gibco, USA) at $37^{\circ} \mathrm{C}$ and $5 \% \mathrm{CO}_{2}$. The culture medium was changed every $2 \mathrm{~d}$, and after they reached $80 \%$ confluency they were digested with trypsin (Gibco, USA). Cells were used after the third to fifth generation. The osteogenic medium (Cyagen, USA) consisted of $87 \%$ SD MSC osteogenic differentiation basal medium, 10\% FBS, 1\% penicillin - streptomycin, $1 \% \beta$-glycerophosphate, $1 \% \mathrm{~L}$ glutamine, $0.2 \%$ ascorbic acid and $0.01 \%$ dexamethasone. The basic medium was a-MEM medium (Gibco, USA) with 10\% fetal bovine serum (Gibco, USA) and 1\% penicillin/streptomycin (Gibco, USA). To 
study the role of the $\mathrm{P} 2 \mathrm{Y} 6$ receptor in osteogenic differentiation of BMSCs, the following reagents were used: P2Y6 specific antagonist MRS 2578 (MedChemExpress, USA) $(10 \mu \mathrm{M}), \mathrm{P} 2 \mathrm{Y} 6$ selective agonist Uridine-5'-diphosphate (UDP) disodium salt (MedChemExpress, USA) $(50 \mu \mathrm{M}, 100 \mu \mathrm{M}$, and $200 \mu \mathrm{M}), \mathrm{PKC}$ specific inhibitor Staurosporine (Beyotime, China) (10 nM). MRS2578, UDP, and Staurosporine were all dissolved in dimethyl sulfoxide and added to the cell culture medium $1 \mathrm{~h}$ before use.

This study has been approved by the Ethics Committee of the Second Hospital of Anhui Medical University.

\section{(4) RNA extraction and Quantitative Real-Time PCR (qRT-PCR) analysis}

Total RNA was extracted from BMSCs using Trizol reagent (Invitrogen, USA) and reverse-transcribed into cDNA using PrimeScriptTM cDNA synthesis kit (6210A Takara, Japan). Real-time polymerase chain

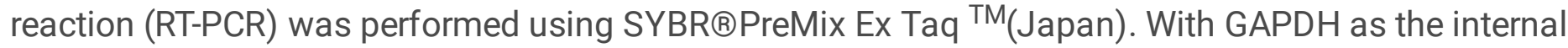
control, and the relative GAPDH expression was calculated using the $2^{-\triangle \Delta C t}$ method and the primer sequences are shown in Table 1.

Table 1

Primers used in GRT-PCR detection

\begin{tabular}{|c|c|c|}
\hline Genes & Forward $\left(5^{\square}-3^{\square}\right)$ & Reverse $\left(5^{\square}-3^{\square}\right)$ \\
\hline P2Y6 & TCCTTACCGCATGGGGAGTA & GTGGGTTCTCGGGAAGTGAG \\
\hline OPN & CCAGCCAAGGACCAACTACA & AGTGTTTGCTGTAATGCGCC \\
\hline RUNX2 & GCGGTGCAAACTTTCTCCAG & ССTTAAATATTACTGCATGGACTGT \\
\hline ALP & GTGGTATTGTAGGTGCTGTGGTC & CGGTGTCGTAGCCTTCTGG \\
\hline $\mathrm{OCN}$ & TCAACAATGGACTTGGAGCCC & GCAACACATGCCCTAAACGG \\
\hline $\mathrm{PKCa}$ & AGCACTCCCATCTTCAGTCC & СTTССTСTTCTСTCCTGGCAT \\
\hline ERK1/2 & CGATGGTGGGGCATCGTGAA & TGCCACTTGCACTCTCGAAC \\
\hline GAPDH & TTTAGGGGCGCTGGTGC & TACGGCCAAATCCGTTCACA \\
\hline
\end{tabular}

\section{(5) Western Blotting}

BMSCs were cultured on $\mathrm{TiO}_{2}$ nanotubes and isolated with trypsin (Gibco, USA), then washed with PBS three times, and lysed with RIPA buffer (with added protease and phosphatase inhibitors) on ice for 30 min. Then, $15 \mu \mathrm{L}$ samples were separated by $10 \%$ sodium dodecyl sulfate-polyacrylamide gel electrophoresis and electro-transferred onto nitrocellulose membranes. The main antibodies used were rabbit anti-P2Y6 polyclonal antibody 1:1000, AB2838912, rabbit anti-OPN monoclonal antibody 1:1000, AB2833402, rabbit anti-RUNX2 monoclonal antibody 1:1000, AB2837672, rabbit anti-OCN monoclonal antibody 1:1000, AB2845108, rabbit anti-PKCa monoclonal antibody 1:1000, AB2835077, rabbit anti- 
ERK1/2 monoclonal antibody 1:1000, AB2833336, and rabbit anti-phosphorylated-ERK1/2 monoclonal antibody 1:1000, AB2834432, all from Affinity Bioreagents, USA. The protein load was standardized by using GAPDH antibody (1:1000, AB283942, Affinity Bioreagents, USA) and protein bands were determined by Image J1.48v software and normalized into corresponding GAPDH bands. The change of target protein expression was expressed by the relative density of each target protein normalized to the control group.

\section{(6) Statistical analysis}

GraphPad Prism7.0 was used for statistical analysis and data were expressed as averages \pm SD. Nonparametric test was used for comparison between the two groups. $\mathrm{P}<0.05$ represented statistical significance.

\section{Results}

\section{(1) Surface morphology of the $\mathrm{TiO}_{2}$ nanotubes}

$\mathrm{TiO}_{2}$ nanotubes were prepared by continuous oxidation of titanium wafers at different constant voltages for $1 \mathrm{~h}$ using anodizing technology. Scanning electron microscopy SEM showed that uniformly distributed nanotube arrays were formed on titanium sheets (Figure 1A). The average inner diameters of the nanotubes were about $57 \mathrm{~nm}(30 \mathrm{~V}), 86 \mathrm{~nm}(50 \mathrm{~V}), 111 \mathrm{~nm}(70 \mathrm{~V})$, and $135 \mathrm{~nm}$ (90 V, Figure 1B). This shows that the average inner diameter of the nanotubes is related to the anodizing voltage. In a certain range, the inner diameter of the nanotubes increases with an increase in oxidation voltage and the composition of the nanotubes was analyzed by X-ray energy dispersive spectroscopy (EDS). The results show that the nanotubes are composed of $\mathrm{O}$ and Ti only (Figure 1C).

(2) $\mathrm{TiO}_{2}$ nanotubes with different diameters can promote the expression of P2Y6 during the osteogenic differentiation of BMSCs

BMSCs were sedimented onto pure titanium sheets or $\mathrm{TiO}_{2}$ nanotubes with different diameters $(30,50$, 70 , and $90 \mathrm{~V}$ ). After culture in an osteogenic induction environment for $3 \mathrm{~d}, 7 \mathrm{~d}$, and $14 \mathrm{~d}$, the expression of P2Y6 at the mRNA level was detected by qRT-PCR, and the expression of P2Y6 at the protein level was detected by western blot. We found that at different time points, when compared to the pure titanium group, the expression of $\mathrm{P} 2 \mathrm{Y} 6$ in the $\mathrm{BMSCs}$ sedimented onto $\mathrm{TiO}_{2}$ nanotubes increased at different levels (Figure 2A, B). Among these, the $70 \mathrm{~V}$ group showed the highest increase in P2Y6 expression and was therefore used for further studies.

(3) $\mathrm{TiO}_{2}$ nanotubes can promote BMSC expression of P2Y6 in an osteogenic induction environment, but not in a conventional culture environment

To examine the expression conditions and timing of the $\mathrm{P} 2 \mathrm{Y} 6$ receptor induced by $\mathrm{TiO}_{2}$ nanotubes, we seeded $\mathrm{BMSC}$ from $70 \mathrm{~V}-\mathrm{TiO}_{2}$ nanotubes and cultured them for $0,1,3,7$, and $14 \mathrm{~d}$ using basal medium and osteogenic induction medium, respectively. From this, qRT-PCR analysis showed that the $\mathrm{TiO}_{2}$ 
nanotubes did not affect the expression of P2Y6 in BMSCs using basic medium. In contrast, when osteogenic induction culture conditions were used, the gene expression of P2Y6 from BMSCs increased on day 3 and more than doubled on days 7-14. This effect was significantly enhanced by exposure to $\mathrm{TiO}_{2}$ nanotubes. BMSCs cultured in contact with $\mathrm{TiO}_{2}$ nanotubes in osteogenic medium showed a twofold increase in P2Y6 gene expression on the 3rd day, and a further increase on days 7-14 (Figure 3A). Western blot analysis showed no significant difference in P2Y6 expression between BMSCs cultured in basal medium with or without $\mathrm{TiO}_{2}$ nanotube exposure at different time points. In BMSCs cultured in osteogenic induction medium, P2Y 6 protein expression increased by $50 \%$ by $14 \mathrm{~d}$, but in the presence of $\mathrm{TiO}_{2}$ nanotubes, it increased 3-4-fold by day 14 (Figure 3B). These results suggest that $\mathrm{TiO}_{2}$ nanotubes significantly promoted the expression of $\mathrm{P} 2 \mathrm{Y} 6$ in BMSCs during osteogenic differentiation.

\section{(4) P2Y6 expression is linked to $\mathrm{TiO}_{2}$ nanotubes-enhanced osteogenic differentiation in BMSCs}

In this study, we confirmed the effects of $\mathrm{TiO}_{2}$ nanotube treatment in osteogenic medium on the osteogenic effects of BMSCs. We also used MRS2578, a specific antagonist of P2Y6, to determine whether this effect is related to the expression of P2Y6. Furthermore, qRT-PCR analysis showed that after BMSCs were sedimented onto the surface of the $\mathrm{TiO}_{2}$ nanotubes and cultured in osteogenic induction medium for $7 \mathrm{~d}$, the gene expression of osteogenesis-related markers (OPN, RUNX2, ALP and OCN) increased significantly and MRS2578 $(10 \mu \mathrm{M})$ treatment could significantly reduce this effect. Compared with the pure titanium group, the use of MRS2578 alone had no effect on the expression of osteogenic genes (Figure 4A) and the results from western blot analysis were consistent with those of qRT-PCR. After the BMSCs were cultured with the $\mathrm{TiO}_{2}$ nanotubes for 7 days, the expression of osteogenesis-related markers (OPN, RUNX2 and OCN) increased 3-4 times, but when MRS2578 was present, the $\mathrm{TiO}_{2}$ nanotubes significantly decreased the expression of osteogenesis-related markers (Figure 4B). These results suggest that the mechanism by which $\mathrm{TiO}_{2}$ nanotubes promote osteogenic differentiation of BMSCs is at least in part related to the expression of P2Y6.

(5) Upregulation of P2Y6 expression induced by $\mathrm{TiO}_{2}$ nanotubes promotes osteogenic differentiation of BMSCs through the PKCa-ERK1/2 signal pathway.

Next, we studied the role of the PKCa-ERK1/2 signal pathway in the upregulation of P2Y6 expression induced by $\mathrm{TiO}_{2}$ nanotubes in the promotion of osteogenic differentiation. Western blot results showed that the levels of P2Y6, PKCa and phosphorylated ERK1/2 increased after BMSCs were stimulated with $\mathrm{TiO}_{2}$ nanotubes, but this effect was weakened when P2Y6 was blocked by MRS2578. Staurosporine (10 nM), a PKC blocker, could inhibit the upregulation of PKCa and phosphorylated ERK1/2 induced by the $\mathrm{TiO}_{2}$ nanotubes, but had no effect on P2Y6 expression. Compared to Staurosporine alone, combined treatment MRS2578 and Staurosporine did not produce additional inhibitory effect (Figure 5A). The results of qRT-PCR and western blot analysis showed that the expression of osteogenic markers (OPN, RUNX2, ALP and OCN) increased at both the mRNA and protein levels after $\mathrm{TiO}_{2}$ nanotube treatment. MRS2578 and Staurosporine could partially inhibit the expression of osteogenic markers, but the 
inhibitory effect of Staurosporine was greater. The inhibitory effect of MRS2578 and Staurosporine on the expression of osteogenic markers was the same as that of Staurosporine alone (Figure 5B, C). These results suggest that $\mathrm{P} 2 \mathrm{Y} 6$ acts upstream of $\mathrm{PKCa}-\mathrm{ERK} 1 / 2$ signaling and is partially involved in the osteogenic differentiation of BMSCs induced by $\mathrm{TiO}_{2}$ nanotubes.

\section{(6) Activation of P2Y6 can enhance osteogenesis of BMSCs promoted by $\mathrm{TiO}_{2}$ nanotubes}

After confirmation that $\mathrm{P} 2 \mathrm{Y} 6$ is involved in osteogenic differentiation caused by $\mathrm{TiO}_{2}$ nanotubes, we then used the P2Y6 agonist UDP $(50 \mu \mathrm{M} 100 \mu \mathrm{M} 200 \mu \mathrm{M})$ to study the effect of activating P2Y6 on the enhanced osteogenic effect of $\mathrm{TiO}_{2}$ nanotubes. After $7 \mathrm{~d}$ of osteogenic induction alone, stimulation with $\mathrm{TiO}_{2}$ nanotubes caused an upregulation in the expression of osteogenic markers (OPN, RUNX2, ALP, and $\mathrm{OCN}$ ) at both the mRNA and protein when in the presence of a P2Y6 activator (Figure 6A, B). In all groups, $\mathrm{TiO}_{2}$ nanotubes combined with $100 \mu \mathrm{M}$ UDP exhibited the greatest osteogenic effect, and its expression level was significantly higher than that of $\mathrm{TiO}_{2}$ nanotubes or $100 \mu \mathrm{M}$ UDP alone. These results suggest that $\mathrm{P} 2 \mathrm{Y} 6$ activation can enhance the osteogenic effect of $\mathrm{TiO}_{2}$ nanotubes on BMSCs.

\section{Discussion}

Osseointegration refers to the ordered structural and functional connection between the surface of the implant and the bone of the host [19]. The degree of osseointegration between implant and bone is the decisive parameter for determining the success of implant treatment. Because of the favorable properties of titanium, titanium and titanium alloys are the most widely used metal materials used for orthopedic implants. However, the biological inertia of titanium implants often affects osseointegration, resulting in implantation failure [20]. Therefore, it is of great scientific and social significance to improve the osseointegration effect of titanium and its alloys when implanted at the host bone-implant interface.

The closely arranged $\mathrm{TiO}_{2}$ nanotubes can be formed on the surface of titanium by chemical oxidation modification. This kind of nanotube micromorphology can not only improve its corrosion resistance, wear resistance and mechanical properties, but also promote the differentiation of BMSCs into osteoblasts playing an active role in enhancing the osseointegration effect of host bone-implant interface [21]. However, the mechanism by which $\mathrm{TiO}_{2}$ nanotubes promote the osteogenic differentiation of BMSCs has not been fully elucidated.

Among the possible molecular mechanisms associated with $\mathrm{TiO}_{2}$ nanotubes, one popular theory relates to the activation of mechanical stimulation pathways [21]. Deformation occurs when BMSCs are attached to the surface of nanostructures, resulting in different degrees of cellular tension. Extracellular physical stimulation is then transformed into intracellular biochemical signals through the relevant receptors on the cell membrane, which in turn affects gene expression [22]. Whereas the molecular mechanisms mediating the conversion of mechanical stimuli into biochemical signals remain poorly understood. Extracellular nucleotides (such as ATP, ADP, UTP and UDP) can be released as autocrine/paracrine mediators of osteoblasts under mechanical stimulation, acting as extracellular 
signaling molecules and can interact with specific purinergic receptors and mediate a variety of processes including neurotransmission, inflammation, apoptosis, and bone remodeling [23-25]. Determined by ligand specificity, purinergic receptors are divided into P1 (ligand - adenosine) or P2 receptors (ligands - ATP and its analogues). More recently based on molecular structure and signaling pathway activation preference, the $\mathrm{P} 2$ receptor family has been divided into two subfamilies: the P2X and P2Y receptors. To date, seven $P 2 X(P 2 X 1-7)$ and eight $P 2 Y(P 2 Y 1,2,4,6,11,12,13$, and 14) receptors have been identified, each of which has been cloned, tissue expression pattern determined and pharmacological function revealed [26]. Among them, the P2Y receptor has been shown to play an important role in the osteogenic differentiation of BMSCs [27]. Some studies have found that extracellular nucleotides increase the mRNA levels of alkaline phosphatase (ALP), bone morphogenetic protein (BMP) and bone sialoprotein (BSP) in rat osteoblasts by activating the P2Y receptor and promoting ALP activity and bone mineralization [28]. A variety of $\mathrm{P} 2 \mathrm{Y}$ receptors have been detected in human bone tissue, for example the expression level of P2Y6 is very high [29] and this receptor, a member of P2Y family, is highly selective for nucleotides containing uridine, such as UDP. P2Y6 receptors are expressed in bone, brain, kidney, heart, and many other tissues, but are particularly important for bone development and repair [30, 31]. $P 2 Y 6$ can activate phospholipase $C$ (PLC) by binding to ligands in osteoblasts, which subsequently leads to an increase of intracellular free $\mathrm{Ca}^{2+}$ and the activation of protein kinase $\mathrm{C}(\mathrm{PKC})$, which regulates cell proliferation and differentiation, while in osteoclasts, the activation of P2Y6 receptor prevents TNF a-induced apoptosis [31-33]. It was found that the activation of P2Y6 receptor significantly increased the content of $\mathrm{Ca}^{2+}$ and the activity of ALP in BMSCs, while the expression of ALP decreased significantly after inhibition of P2Y6 activity [17].

$\mathrm{TiO}_{2}$ nanotubes are widely used and are effective at promoting osteogenic differentiation of BMSCs. We hypothesized that $\mathrm{TiO}_{2}$ nanotubes could promote osteogenic differentiation of BMSCs by upregulating the expression of P2Y6. Thus, we compared the expression of $\mathrm{P} 2 \mathrm{Y} 6$ in BMSCs stimulated by $\mathrm{TiO}_{2}$ nanotubes and pure titanium flakes. Next, we detected the culture conditions and timing of P2Y6 expression induced by the $\mathrm{TiO}_{2}$ nanotubes. The P2Y6 mRNA and protein levels of BMSCs cultured in basic medium did not change significantly during a $14 \mathrm{~d}$ treatment with $\mathrm{TiO}_{2}$ nanotubes. This showed that under conventional culture conditions, $\mathrm{TiO}_{2}$ nanotubes do not affect the expression of $\mathrm{P} 2 \mathrm{Y} 6$. We speculate that the transcription of the P2Y6 gene is inactive under conventional culture conditions, which leads to insensitivity to $\mathrm{TiO}_{2}$ nanotubes. Therefore, we detected $\mathrm{P} 2 \mathrm{Y} 6$ expression of BMSCs during osteogenic differentiation in the presence or absence of $\mathrm{TiO}_{2}$ nanotubes. Surprisingly, the mRNA and protein content of $\mathrm{P} 2 \mathrm{Y} 6$ in the $\mathrm{TiO}_{2}$ nanotube treated group were significantly higher than those in the pure titanium group at 3,7 , and $14 \mathrm{~d}$ after osteogenic induction. These results suggest that $\mathrm{TiO}_{2}$ nanotubes can further enhance the upregulation of $\mathrm{P} 2 \mathrm{Y} 6$ expression during osteogenic differentiation of BMSCs.

To further verify a role for the upregulated $\mathrm{P} 2 \mathrm{Y} 6$ expression caused by the $\mathrm{TiO}_{2}$ nanotubes during osteogenic differentiation of BMSCs, we analyzed the effect of $\mathrm{TiO}_{2}$ nanotubes combined with $\mathrm{P} 2 \mathrm{Y} 6$ 
inhibitors on the osteogenic differentiation of BMSCs. P2Y6 inhibitors had no obvious inhibitory effect on the osteogenic differentiation of BMSCs when pure titanium tablets were used, but significantly reduced the osteogenic effect of $\mathrm{TiO}_{2}$ nanotubes. These results suggest that the overexpression of $\mathrm{P} 2 \mathrm{Y} 6$ stimulated by $\mathrm{TiO}_{2}$ nanotubes enhances the osteogenic capacity of BMSCs, which may be why $\mathrm{TiO}_{2}$ nanotubes promote osteogenic differentiation. However, the signaling pathway involved in the upregulation of $\mathrm{P} 2 \mathrm{Y} 6$ expression induced by $\mathrm{TiO}_{2}$ nanotubes and the subsequent promotion the osteogenic differentiation in BMSCs is not clear.

Many signaling pathways have been identified to be involved in the differentiation of BMSCs, including wingless-type MMTV integration site (Wnt) signaling, transforming growth factor-beta (TGF- $\beta$ )/bone morphogenetic protein (BMP), mitogen-activated protein kinase (MAPKs), Hedgehogs (Hh), and Notch and RhoA/ROCK pathways $[34,35]$. Among these signaling pathways, MAPKs play an important role in regulating the osteogenic differentiation of BMSCs [36]. This signaling pathway is a classical pathway, which can transmit cell surface signals to the nucleus in response to various stimuli such as surface structure, hormonal, and stress, and plays an important role in cell biological responses such as cell proliferation, differentiation, transformation, and apoptosis [37]. At present, three main MAPK signaling transduction pathways have been found in mammalian cells: P38 MAPK pathway, Jun-terminal kinase (JNKs) pathway and extracellular signal regulated kinase (ERKs) [38]. Among them, the ERK MAPK signaling pathway mainly plays the role in intracellular and extracellular signaling pathways, which can be activated by various extracellular stimuli and mechanical stress, and can regulate cell proliferation, differentiation, and migration and is closely related to the regulation of osteogenic differentiation of BMSCs [39]. Previous studies have shown that porous titanium can upregulate the expression of osteogenic genes such as OSX, Coll, OSN, and OCN by activating the ERK MAPK signal pathway, and promote the osteogenic differentiation of BMSCs [37]. In BMSCs derived from ovariectomized rats, induction of mechanical stress may promote osteogenic differentiation of BMSCs through this pathway, but not through the P38 MAPK or JNKs MAPK signaling pathways [40]. Qi et al. found that fibroblast growth factor 2 (FGF2) promotes the osteogenic differentiation of BMSCs by increasing the level of ERK phosphorylation and activation of the ERK MAPK pathway [41].

Some studies have shown that protein kinase C (PKC) is a key element in the connection between P2Y6 receptor and the ERK MAPK pathway [42]. PKC is a member of the phospholipid-dependent serine/threonine protein kinase family, which can activate extracellular signal-regulated kinase ERK, thus regulating cell differentiation, mitosis, proliferation, and even some abnormal physiological processes, such as tumorigenesis, resulting in a wide range of biological effects [43]. PKCa is a $\mathrm{Ca}^{2+}$-dependent subtype and the increase in intracellular $\mathrm{Ca}^{2+}$ causes PKCa to locate to the cell membrane, and then phosphorylate ERK. Li et al. found that Ca-Si-coated titanium implants could promote the phosphorylation of PKC and ERK1/2, increase the activity of ALP, increase mineralized nodule formation, osteoblast-related gene expression, and promote the early osteogenic differentiation of BMSCs [44]. Similarly, electrical stimulation can activate the ERK pathway to regulate the osteogenic differentiation of BMSCs through the $\mathrm{Ca}^{2+}$-mediated PKC signaling pathway [45]. The abnormal influx of intracellular $\mathrm{Ca}^{2+}$ 
can downregulate the expression of PKC-ERK signal, inhibit the osteogenic differentiation of BMSCs, and lead to osteoporosis [46]. Previous studies have shown that under the stimulation by its agonist UDP, $\mathrm{P} 2 \mathrm{Y} 6$ receptor activation can increase intracellular $\mathrm{Ca}^{2+}$ concentration and PKC activation, and then induce ERK phosphorylation within the MAPK pathway [47]. The addition of PKC inhibitors can partially antagonize the activation of UDP and reduce the level of UDP-induced ERK phosphorylation [48]. Muscella et al. found that inhibition of PKC activity in HeLa cells had a significant effect on P2Y6induced ERK phosphorylation [42].

In this study, $\mathrm{TiO}_{2}$ nanotube stimulation activated the $\mathrm{PKCa}-\mathrm{ERK} 1 / 2$ signal pathway, increased the expression of osteogenesis-related markers, and promoted the osteogenic differentiation of BMSCs (Figure 7). P2Y6 antagonist such as MRS 2578 and the PKC specific inhibitor Staurosporine could partially inhibit the above effects but had no effect on P2Y6 expression. Furthermore, the inhibitory effect of Staurosporine was greater than that of MRS 2578.

Based on our findings, we were able to optimize the osteogenic effect of $\mathrm{TiO}_{2}$ nanotubes by activating P2Y6. Our in vitro data confirmed that the application of P2Y6 agonist UDP could enhance the osteogenesis of nanotubes.

\section{Conclusions}

In the process of osteogenic differentiation of BMSCs, contact with $\mathrm{TiO}_{2}$ nanotubes can stimulate the upregulation of $\mathrm{P} 2 \mathrm{Y} 6$ expression in these cells. The osteogenic effect of $\mathrm{TiO}_{2}$ nanotubes is partly due to the increased expression of $\mathrm{P} 2 \mathrm{Y} 6$. $\mathrm{P} 2 \mathrm{Y} 6$ overexpression induced by $\mathrm{TiO}_{2}$ nanotubes promotes the osteogenic differentiation of BMSCs through the PKCa-ERK1/2 signal pathway. P2Y6 agonist therapy, may therefore represent an effective method of increasing the effect of $\mathrm{TiO}_{2}$ nanotubes on the osteogenic differentiation of BMSCs.

\section{Abbreviations}

ALP: alkaline phosphatase; BMP: bone morphogenetic protein; BMSCs: bone marrow mesenchymal stem cells; BSP: bone sialoprotein; EDS: energy dispersive spectroscopy; ERKs: extracellular signal regulated kinase; FGF2: fibroblast growth factor 2. Hh: Hedgehogs; JNKs: Jun-terminal kinase ; MAPKs: mitogenactivated protein kinase; PKC: protein kinase C; PLC: phospholipase C; qRT-PCR: Quantitative reverse transcriptase polymerase chain reaction; SEM: scanning electron microscope ; TGF- $\beta$ : transforming growth factor-beta; Ti: titanium; $\mathrm{TiO}_{2} \mathrm{\square T}$ itanium dioxide; WB: western blotting; Wnt: wingless-type MMTV integration site.

\section{Declarations}

Ethics approval and consent to participateINot applicable 
Consent for publication $\square$ Not applicable

Availability of data and materials[The datasets used and/or analysed during the current study are available from the corresponding author on reasonable request.

Competing interests[The authors declare that they have no competing interests

Funding $\square$ The funding source is provided by Hefei Science and Technology Bureau, Fund number: J2020Y07.

Authors' contributions $\square \mathrm{CW}$, and $\mathrm{YL}$ contributed to conception and design of the study. CW , HG and XS performed the statistical analysis. CW and YL wrote the first draft of the manuscript. SM, LG, LL and YZ wrote sections of the manuscript. HY and WC were responsible for the revision of the manuscript for important intellectual content. All authors read and approved the final manuscript.

Acknowledgements: SEM and EDS tests are assisted by shiyanjia lab (www. shiyanjia.com).

\section{References}

1. Dai J, Fu Y, Chen D, Sun Z. A novel and injectable strontium-containing hydroxyapatite bone cement for bone substitution: A systematic evaluation. Mater Sci Eng C Mater Biol Appl. 2021; 124:112052.

2. He Y, Mu C, Shen X, Yuan Z, Liu J, Chen W, et al. Peptide LL-37 coating on micro-structured titanium implants to facilitate bone formation in vivo via mesenchymal stem cell recruitment. Acta Biomater. 2018; 80:412-24.

3. Zhou B, Peng K, Wang G, Chen W, Kang Y. Polo Like Kinase 4 (PLK4) impairs human bone marrow mesenchymal stem cell (BMSC) viability and osteogenic differentiation. Biochem Biophys Res Commun. 2021; 549:221-8.

4. Huo SC, Yue B. Approaches to promoting bone marrow mesenchymal stem cell osteogenesis on orthopedic implant surface. World J Stem Cells. 2020; 12:545-61.

5. Zhang YL, Liu L, Peymanfar Y, Anderson P, Xian CJ. Roles of MicroRNAs in Osteogenesis or Adipogenesis Differentiation of Bone Marrow Stromal Progenitor Cells. Int J Mol Sci. 2021;22.

6. Li L, Yao L, Wang H, Shen X, Lou W, Huang C, et al. Magnetron sputtering of strontium nanolayer on zirconia implant to enhance osteogenesis. Mater Sci Eng C Mater Biol Appl. 2021; 127:112191.

7. Yu X, Xu R, Zhang Z, Jiang Q, Liu Y, Yu X, et al. Different Cell and Tissue Behavior of Micro-/NanoTubes and Micro-/Nano-Nets Topographies on Selective Laser Melting Titanium to Enhance Osseointegration. Int J Nanomedicine. 2021; 16:3329-42.

8. Zhao QM, Sun YY, Wu CS, Yang J, Bao GF, Cui ZM. Enhanced osteogenic activity and antibacterial ability of manganese-titanium dioxide microporous coating on titanium surfaces. Nanotoxicology. 2020; 14:289-309. 
9. Wang Z, Mei L, Liu X, Zhou Q. Hierarchically hybrid biocoatings on Ti implants for enhanced antibacterial activity and osteogenesis. Colloids Surf B Biointerfaces. 2021; 204:111802.

10. Bandyopadhyay A, Shivaram A, Mitra I, Bose S. Electrically polarized TiO2 nanotubes on Ti implants to enhance early-stage osseointegration. Acta Biomater. 2019; 96:686-93.

11. Jorgensen NR. Role of the purinergic $P 2 X$ receptors in osteoclast pathophysiology. Curr Opin Pharmacol. 2019; 47:97-101.

12. Zuccarini M, Giuliani P, Caciagli F, Ciccarelli R, Di lorio P. In Search of a Role for Extracellular Purine Enzymes in Bone Function. Biomolecules. 2021;11.

13. Cuthbertson P, Geraghty NJ, Adhikary SR, Bird KM, Fuller SJ, Watson D, et al. Purinergic Signalling in Allogeneic Haematopoietic Stem Cell Transplantation and Graft-versus-Host Disease. Int J Mol Sci. 2021;22.

14. Kong Q, Quan Y, Tian G, Zhou J, Liu X. Purinergic P2 Receptors: Novel Mediators of Mechanotransduction. Front Pharmacol. 2021; 12:671809.

15. Ottensmeyer PF, Witzler M, Schulze M, Tobiasch E. Small Molecules Enhance Scaffold-Based Bone Grafts via Purinergic Receptor Signaling in Stem Cells. Int J Mol Sci. 2018;19.

16. Carluccio M, Ziberi S, Zuccarini M, Giuliani P, Caciagli F, Di lorio P, et al. Adult mesenchymal stem cells: is there a role for purine receptors in their osteogenic differentiation? Purinergic Signal. 2020; 16:263-87.

17. Noronha-Matos JB, Costa MA, Magalhaes-Cardoso MT, Ferreirinha F, Pelletier J, Freitas R, et al. Role of ecto-NTPDases on UDP-sensitive P2Y(6) receptor activation during osteogenic differentiation of primary bone marrow stromal cells from postmenopausal women. J Cell Physiol. 2012; 227:2694709.

18. Rodrigues-Ribeiro R, Alvarenga EC, Calio ML, Paredes-Gamero EJ, Ferreira AT. Dual role of P2 receptors during osteoblast differentiation. Cell Biochem Biophys. 2015; 71:1225-33.

19. Alipal J, Lee TC, Koshy P, Abdullah HZ, Idris MI. Evolution of anodised titanium for implant applications. Heliyon. 2021;7: e7408.

20. Avila JD, Stenberg K, Bose S, Bandyopadhyay A. Hydroxyapatite reinforced Ti6Al4V composites for load-bearing implants. Acta Biomater. 2021; 123:379-92.

21. Liu Y, Tong Z, Wang C, Xia R, Li H, Yu H, et al. TiO2 nanotubes regulate histone acetylation through Factin to induce the osteogenic differentiation of BMSCs. Artif Cells Nanomed Biotechnol. 2021; 49:398-406.

22. Chang Y, Shao Y, Liu Y, Xia R, Tong Z, Zhang J, et al. Mechanical strain promotes osteogenic differentiation of mesenchymal stem cells on $\mathrm{TiO} 2$ nanotubes substrate. Biochem Biophys Res Commun. 2019; 511:840-6.

23. Ihara $H$, Hirukawa $K$, Goto S, Togari A. ATP-stimulated interleukin-6 synthesis through P2Y receptors on human osteoblasts. Biochem Biophys Res Commun. 2005; 326:329-34. 
24. Manaka S, Tanabe N, Kariya T, Naito M, Takayama T, Nagao M, et al. Low-intensity pulsed ultrasound-induced ATP increases bone formation via the P2X7 receptor in osteoblast-like MC3T3-E1 cells. Febs Lett. 2015; 589:310-8.

25. Schlesinger PH, Blair HC, Beer SD, Riazanski V, Ray EC, Tourkova IL, et al. Cellular and extracellular matrix of bone, with principles of synthesis and dependency of mineral deposition on cell membrane transport. Am J Physiol Cell Physiol. 2020;318:C111-24.

26. Guo X, Li Q, Pi S, Xia Y, Mao L. G protein-coupled purinergic P2Y receptor oligomerization: Pharmacological changes and dynamic regulation. Biochem Pharmacol. 2021; 192:114689.

27. Abbracchio MP, Burnstock G, Boeynaems JM, Barnard EA, Boyer JL, Kennedy C, et al. International Union of Pharmacology LVIII: update on the P2Y G protein-coupled nucleotide receptors: from molecular mechanisms and pathophysiology to therapy. Pharmacol Rev. 2006; 58:281-341.

28. Ayala-Pena VB, Scolaro LA, Santillan GE. ATP and UTP stimulate bone morphogenetic protein-2, -4 and -5 gene expression and mineralization by rat primary osteoblasts involving PI3K/AKT pathway. Exp Cell Res. 2013; 319:2028-36.

29. Maier R, Glatz A, Mosbacher J, Bilbe G. Cloning of P2Y6 cDNAs and identification of a pseudogene: comparison of P2Y receptor subtype expression in bone and brain tissues. Biochem Biophys Res Commun. 1997; 237:297-302.

30. Communi D, Horckmans M, Boeynaems JM. P2Y4, P2Y6 and P2Y11 receptors: From the early days of cloning to their function. Biochem Pharmacol. 2021; 187:114347.

31. Orriss IR, Knight GE, Ranasinghe S, Burnstock G, Arnett TR. Osteoblast responses to nucleotides increase during differentiation. Bone. 2006; 39:300-9.

32. Korcok J, Raimundo LN, Du X, Sims SM, Dixon SJ. P2Y6 nucleotide receptors activate NF-kappaB and increase survival of osteoclasts. J Biol Chem. 2005; 280:16909-15.

33. Orriss IR, Wang N, Burnstock G, Arnett TR, Gartland A, Robaye B, et al. The P2Y (6) receptor stimulates bone resorption by osteoclasts. Endocrinology. 2011;152:3706-16.

34. Chen JC, Jacobs CR. Mechanically induced osteogenic lineage commitment of stem cells. Stem Cell Res Ther. 2013; 4:107.

35. Wang CX, Ma T, Wang MY, Guo HZ, Ge XY, Zhang Y, et al. Facile distribution of an alkaline microenvironment improves human bone marrow mesenchymal stem cell osteogenesis on a titanium surface through the ITG/FAK/ALP pathway. Int J Implant Dent. 2021; 7:56.

36. Yu X, Quan J, Long W, Chen H, Wang R, Guo J, et al. LL-37 inhibits LPS-induced inflammation and stimulates the osteogenic differentiation of BMSCs via P2X7 receptor and MAPK signaling pathway. Exp Cell Res. 2018; 372:178-87.

37. Dou X, Wei X, Liu G, Wang S, Lv Y, Li J, et al. in vitroEffect of porous tantalum on promoting the osteogenic differentiation of bone marrow mesenchymal stem cells through the MAPK/ERK signal pathway. J Orthop Transl. 2019; 19:81-93.

38. Lu J, Li Z, Wu X, Chen Y, Yan M, Ge X, et al. iRoot BP Plus promotes osteo/odontogenic differentiation of bone marrow mesenchymal stem cells via MAPK pathways and autophagy. Stem Cell Res Ther. 
2019; 10:222.

39. Ijomone OM, Iroegbu JD, Aschner M, Bornhorst J. Impact of environmental toxicants on p38- and ERK-MAPK signaling pathways in the central nervous system. Neurotoxicology. 2021.

40. Zhang P, Dai Q, Ouyang N, Yang X, Wang J, Zhou S, et al. Mechanical Strain Promotes Osteogenesis of BMSCs from Ovariectomized Rats via the ERK1/2 but not p38 or JNK-MAPK Signaling Pathways. Curr Mol Med. 2015; 15:780-9.

41. Qi H, Liu Y, Wu L, Ni S, Sun J, Xue J, et al. MicroRNA-16, via FGF2 Regulation of the ERK/MAPK Pathway, Is Involved in the Magnesium-Promoted Osteogenic Differentiation of Mesenchymal Stem Cells. Oxid Med Cell Longev. 2020; 2020:3894926.

42. Muscella A, Greco S, Elia MG, Storelli C, Marsigliante S. Differential signalling of purinoceptors in HeLa cells through the extracellular signal-regulated kinase and protein kinase $\mathrm{C}$ pathways. J Cell Physiol. 2004; 200:428-39.

43. Tsukimoto $M$, Tokunaga $A$, Harada $H$, Kojima S. Blockade of murine $T$ cell activation by antagonists of P2Y6 and P2X7 receptors. Biochem Biophys Res Commun. 2009; 384:512-8.

44. Li K, Hu D, Xie Y, Huang L, Zheng X. Sr-doped nanowire modification of Ca-Si-based coatings for improved osteogenic activities and reduced inflammatory reactions. Nanotechnology. 2018; 29:84001.

45. Shen S, He X, Chen X, Dong L, Cheng K, Weng W. Enhanced osteogenic differentiation of mesenchymal stem cells on P(VDF-TrFE) layer coated microelectrodes. Journal of biomedical materials research. Part B, Applied biomaterials. 2021.

46. Liu Y, Yang R, Liu X, Zhou Y, Qu C, Kikuiri T, et al. Hydrogen sulfide maintains mesenchymal stem cell function and bone homeostasis via regulation of $\mathrm{Ca}(2+)$ channel sulfhydration. Cell Stem Cell. 2014; 15:66-78.

47. Chen BC, Lin WW. PKC- and ERK-dependent activation of I kappa B kinase by lipopolysaccharide in macrophages: enhancement by P2Y receptor-mediated CaMK activation. Brit J Pharmacol. 2001; 134:1055-65.

48. Kim SG, Gao ZG, Soltysiak KA, Chang TS, Brodie C, Jacobson KA. P2Y6 nucleotide receptor activates PKC to protect $1321 \mathrm{~N} 1$ astrocytoma cells against tumor necrosis factor-induced apoptosis. Cell Mol Neurobiol. 2003; 23:401-18.

\section{Figures}


(A)

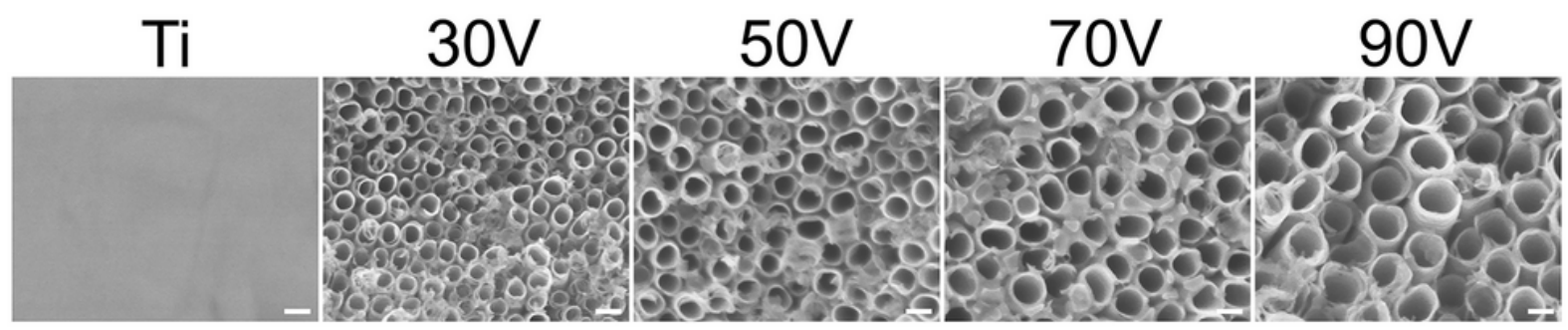

(B)

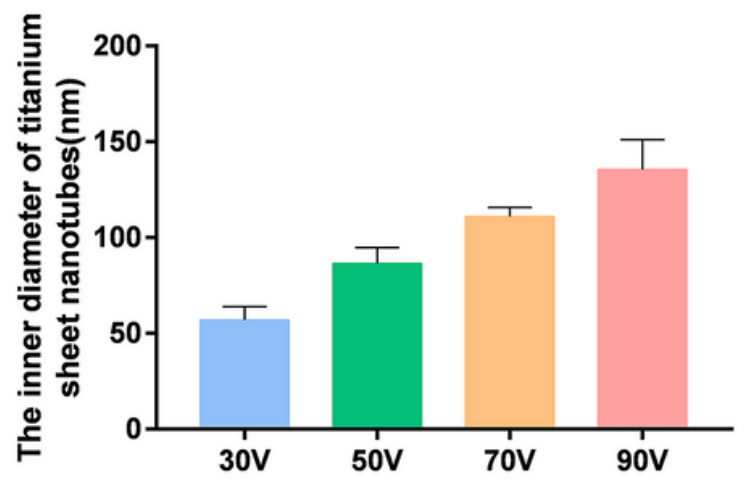

(C)

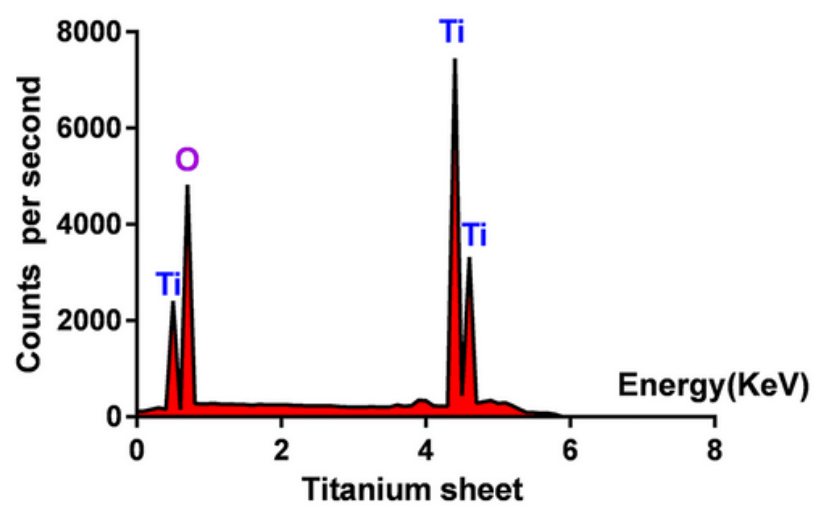

Figure 1

Surface morphology of TiO2 nanotubes. (A) The surface morphology of pure titanium sheets and nanotubes under SEM. Scale bar: $100 \mathrm{~nm}$. (B) The average inner diameters of the TiO2 nanotubes under four different constant voltages ( $30 \mathrm{~V}, 50 \mathrm{~V}, 70 \mathrm{~V}$, and $90 \mathrm{~V})$. (C) The chemical composition of the TiO2 nanotubes. 
(A)

$3 d$

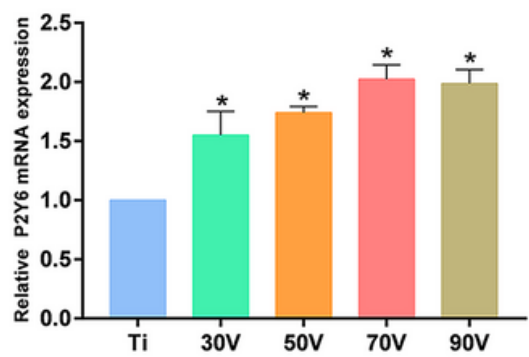

(B)

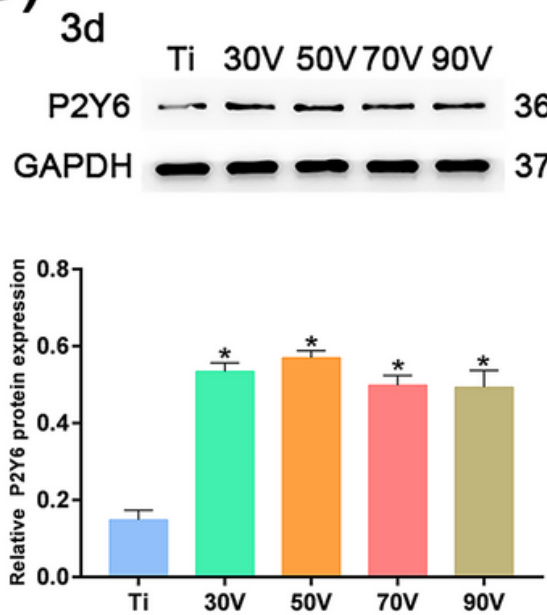

$7 d$

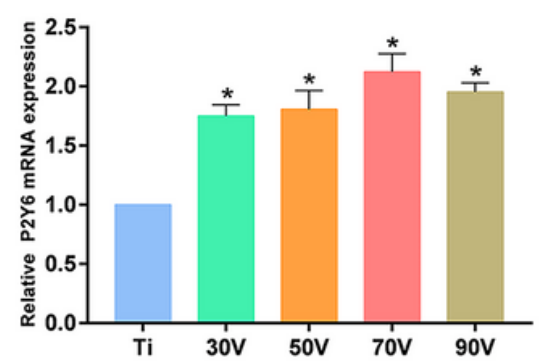

$7 d$

Ti $30 \mathrm{~V} 50 \mathrm{~V} 70 \mathrm{~V} 90 \mathrm{~V}$

$\mathrm{P} 2 \mathrm{Y} 6$ - - - $36 \mathrm{KD}$

$37 \mathrm{KD}$

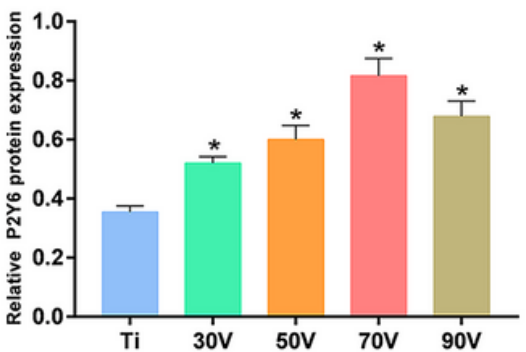

$14 d$

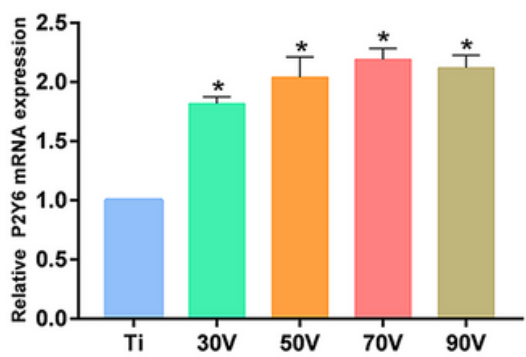

$14 d$

$\mathrm{Ti} 30 \mathrm{~V} 50 \mathrm{~V} 70 \mathrm{~V} 90 \mathrm{~V}$

P2Y6 - - $-36 \mathrm{KD}$

$\mathrm{GAPDH} \longrightarrow 37 \mathrm{KD}$

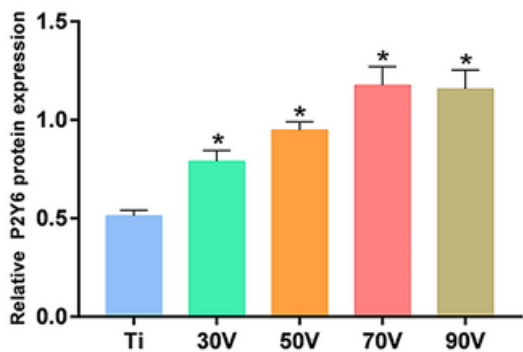

Figure 2

Expression of P2Y6 in BMSCs caused by TiO2 nanotubes of different tube diameter. (A) qRT-PCR and (B) western blot were used to analyze the expression of $\mathrm{P} 2 \mathrm{Y} 6$ after the treatment of BMSCs with nanotubes of different diameters $(30 \mathrm{~V}, 50 \mathrm{~V}, 70 \mathrm{~V}$, and $90 \mathrm{~V})$. The mRNA and protein expression of P2Y6 was normalized against GAPDH. Data represent means \pm SD and statistically significant differences are indicated; $\mathrm{n}=3 ;{ }^{*} \mathrm{P}<0.05$ vs. Ti group. 
(A)

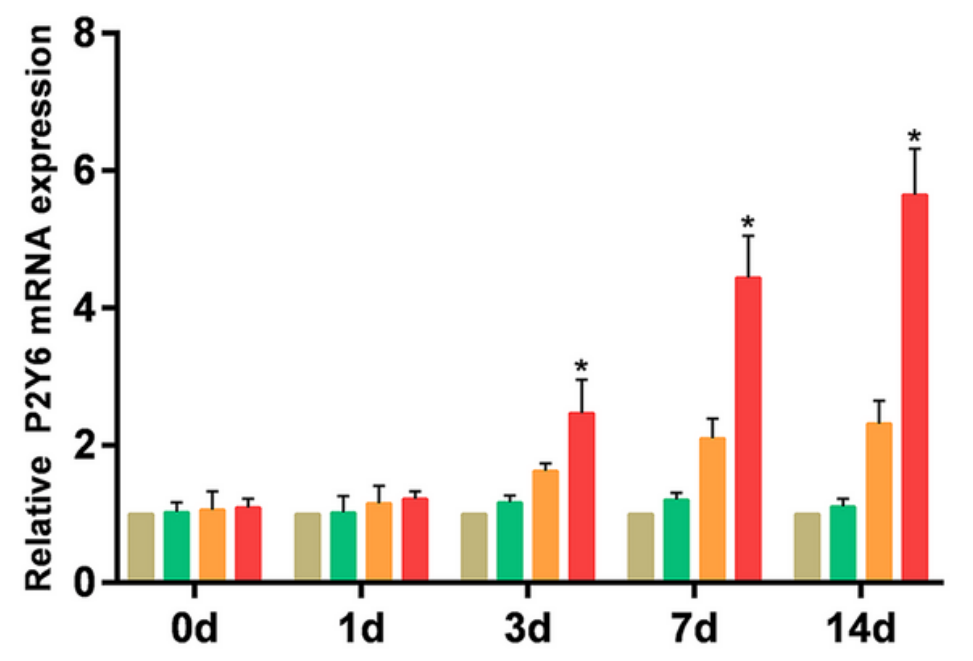

(B)
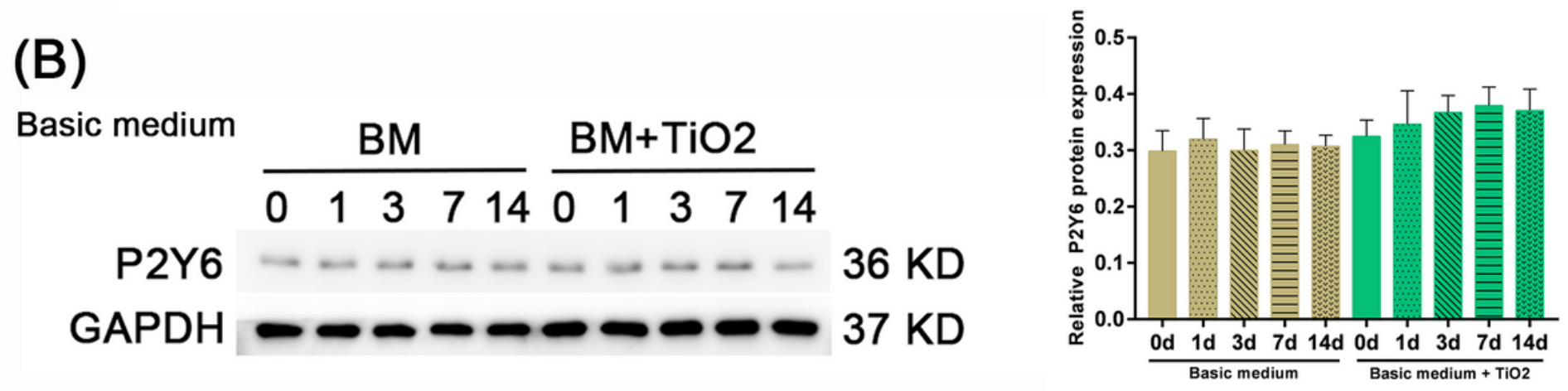

(C)
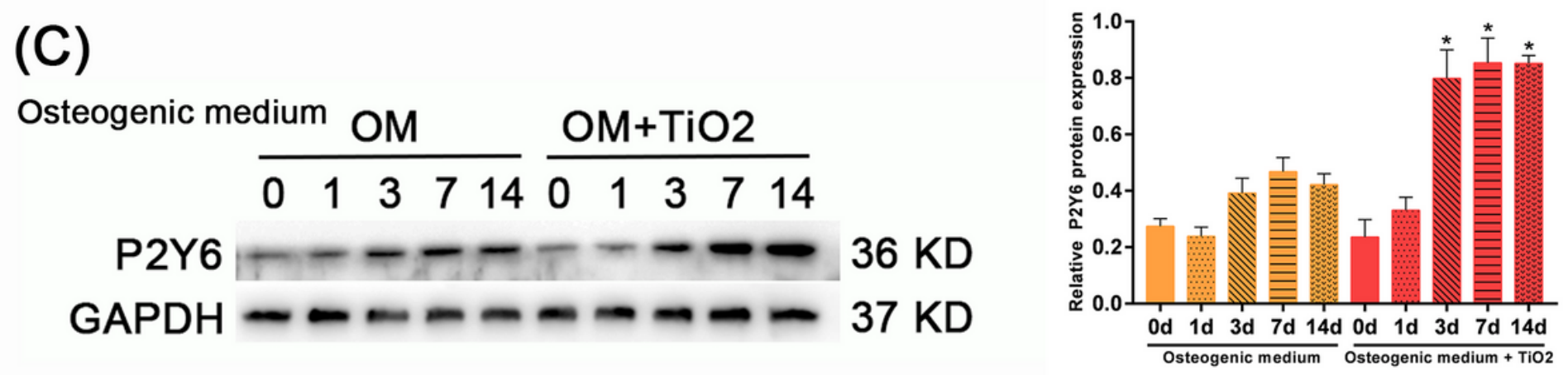

Figure 3

P2Y6 expression in BMSCs under basal and osteogenic medium conditions. (A) QRT-PCR was used to detect the expression of P2Y6 in BMSCs cultured with basic medium, basic medium + TiO2 nanotube, osteogenic medium and osteogenic medium + TiO2 nanotube for $0,1,3,7$, and $14 \mathrm{~d}$. P2Y 6 mRNA expression was normalized against GAPDH. $(B, C)$ Western blot was used to analyze the expression of $\mathrm{P} 2 \mathrm{Y} 6$ in BMSCs treated with basic medium, basic medium + TiO2 nanotubes, osteogenic medium or osteogenic medium + TiO2 nanotubes for 1, 3, 7, and 14 d. P2Y6 protein expression was normalized against GAPDH. Data represent means $\pm S D$ and statistically significant differences are indicated; $n=3$; $* \mathrm{P}<0.05$ vs. $\mathrm{OM}+/ \mathrm{TiO} 2-$ group. 
(A)
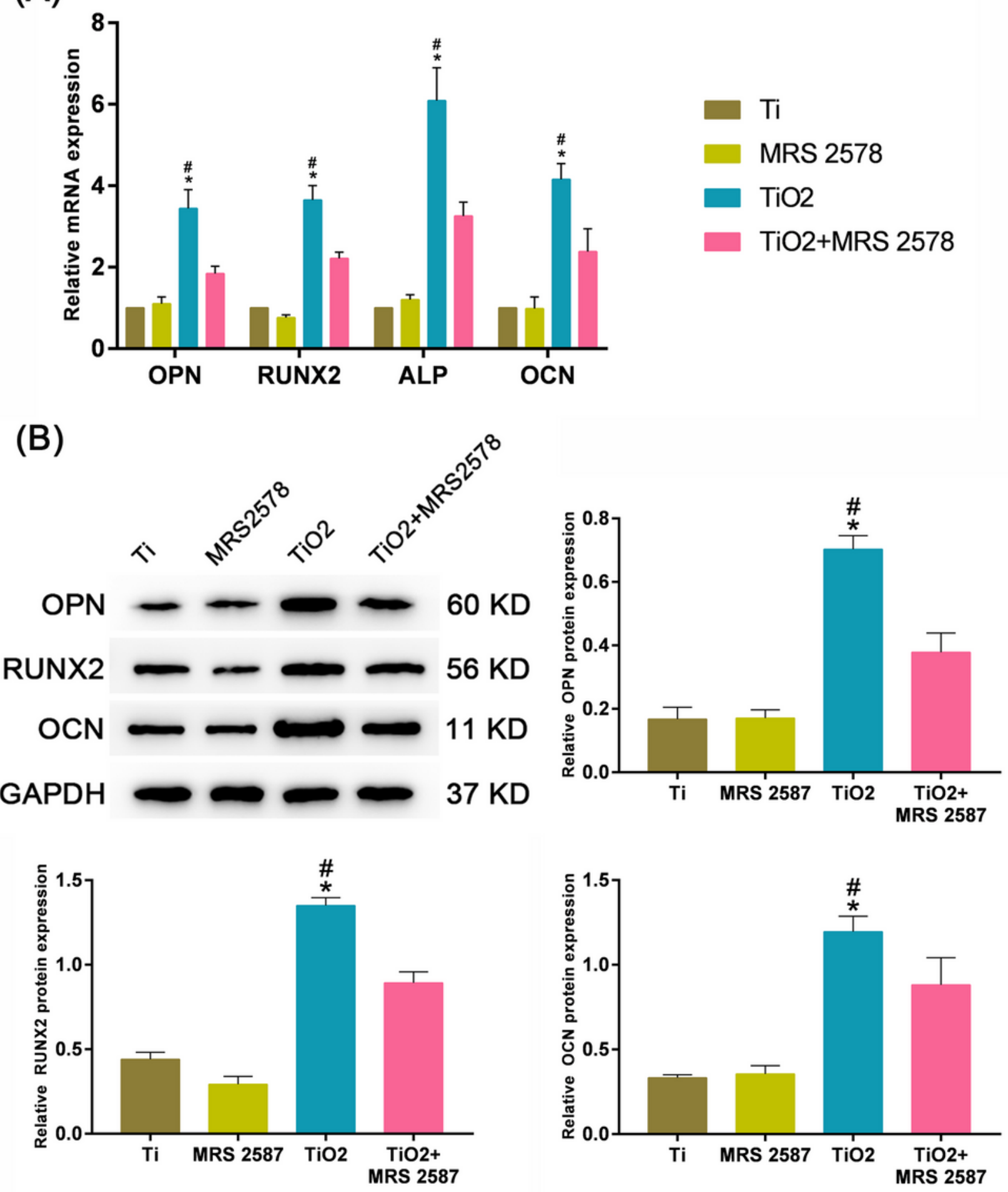

Figure 4

The role of P2Y6 in the osteogenic differentiation of BMSCs promoted by TiO2 nanotubes. (A) After culturing in osteogenic induction medium, osteogenic induction medium + MRS2578, osteogenic medium + TiO2 nanotube, and osteogenic medium + TiO2 nanotube + MRS2578 for $7 \mathrm{~d}$, the expression of osteogenic markers (OPN, RUNX2, ALP, and OCN) in BMSCs was assessed by qRT-PCR. OPN, RUNX2, ALP, and OCN mRNA expression was normalized against GAPDH. (B) cultured in osteogenic medium, 
osteogenic medium + MRS2578, osteogenic medium + TiO2 nanotube, osteogenic medium + TiO2 nanotube + MRS2578 for $7 \mathrm{~d}$, the expression of OPN, RUNX2 and OCN in BMSCs was assessed by western blot. The protein expression of OPN, RUNX2 and OCN was normalized against GAPDH. Data represent means $\pm S D$ and statistically significant differences are indicated; $n=3 ; * P<0.05$ vs. MRS2578 group; \#P $<0.05$ vs. TiO2+ MRS2578 group.

\section{(A)}

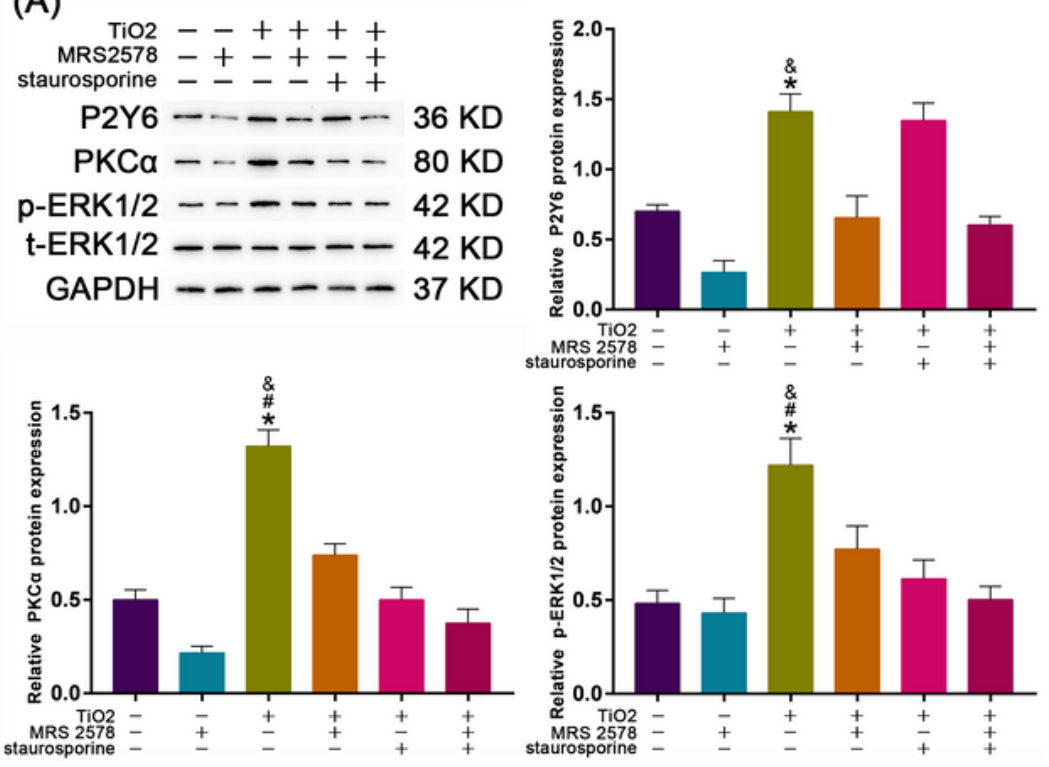

(B)

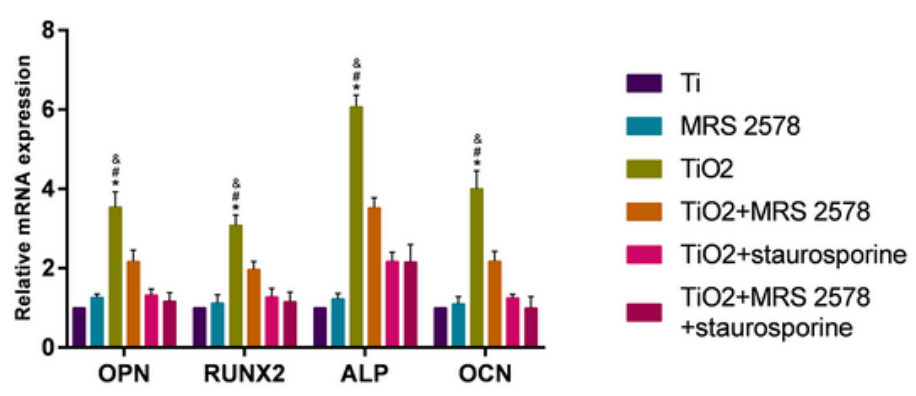

(C)
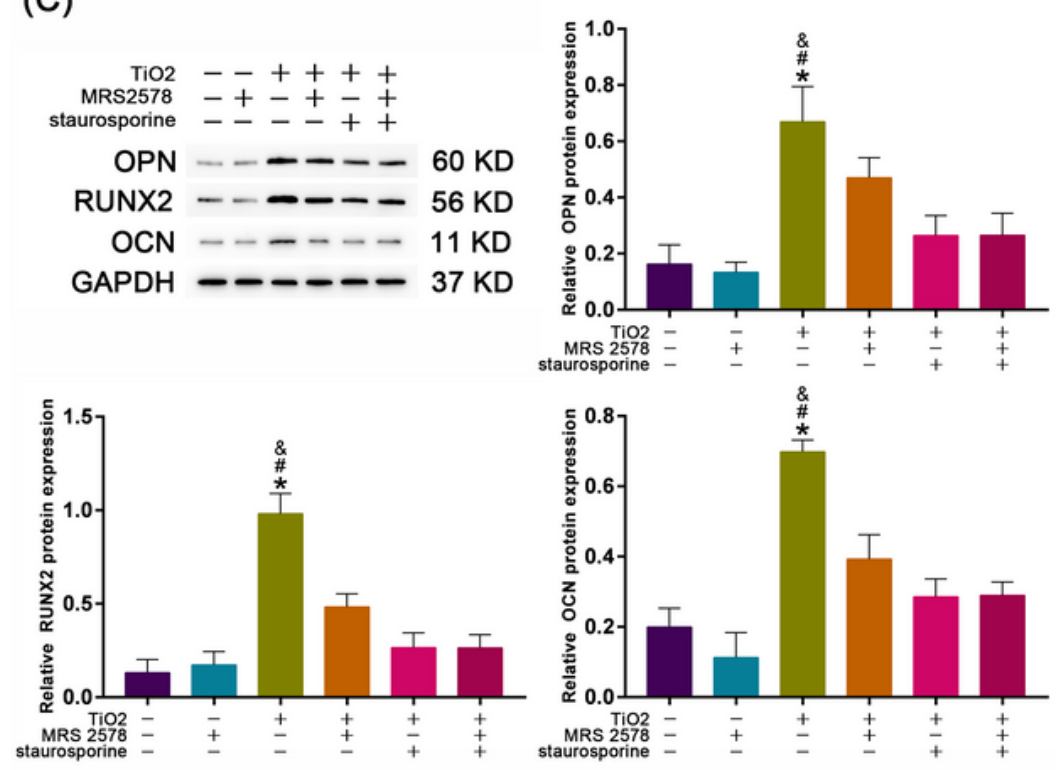

Figure 5 
TiO2 nanotubes upregulate the expression of $\mathrm{P} 2 \mathrm{Y} 6$ and activate the PKCa-ERK1/2 signaling pathway during osteogenic differentiation of BMSCs. (A) Western blot analysis of the effect of nanotubes on the protein expression of P2Y6, PKCa, ERK1/2, and p-ERK1/2 when using MRS2578 and/or Staurosporine. The proteins expression of P2Y6, PKCa, ERK1/2 and p-ERK1/2 were normalized against GAPDH. (B) qRTPCR analysis of the effects of nanotubes on the expression of OPN, RUNX2, ALP, and OCN mRNA when using MRS2578 and/or Staurosporine. The mRNA expression of OPN, RUNX2, ALP and OCN were normalized against GAPDH. (C) Western blot analysis of the effect of nanotubes on the protein expression of OPN, RUNX2, and OCN when using MRS2578 and/or Staurosporine. The proteins expression of OPN, RUNX2 and OCN were normalized against GAPDH. Data represent means \pm SD and statistically significant differences are indicated; $n=3 ;{ }^{*}<0.05$ vs. TiO2+MRS2578 group; \#P $<0.05$ vs. TiO2 + Staurosporine group; \& P $<0.05$ vs. TiO2 + MRS 2578 + Staurosporine group. 
(A)

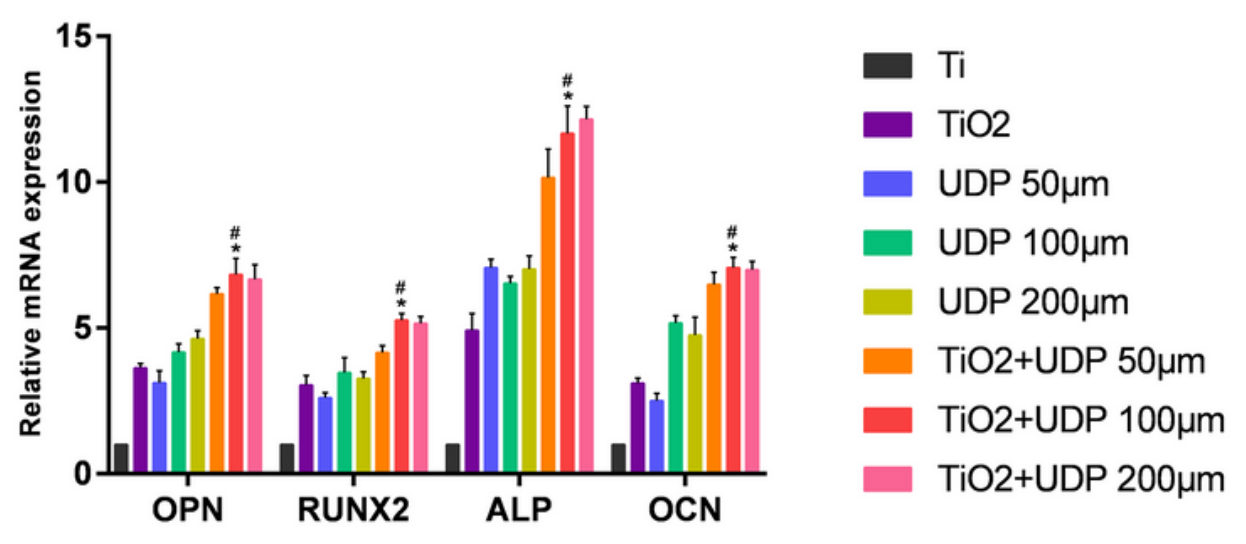

(B)
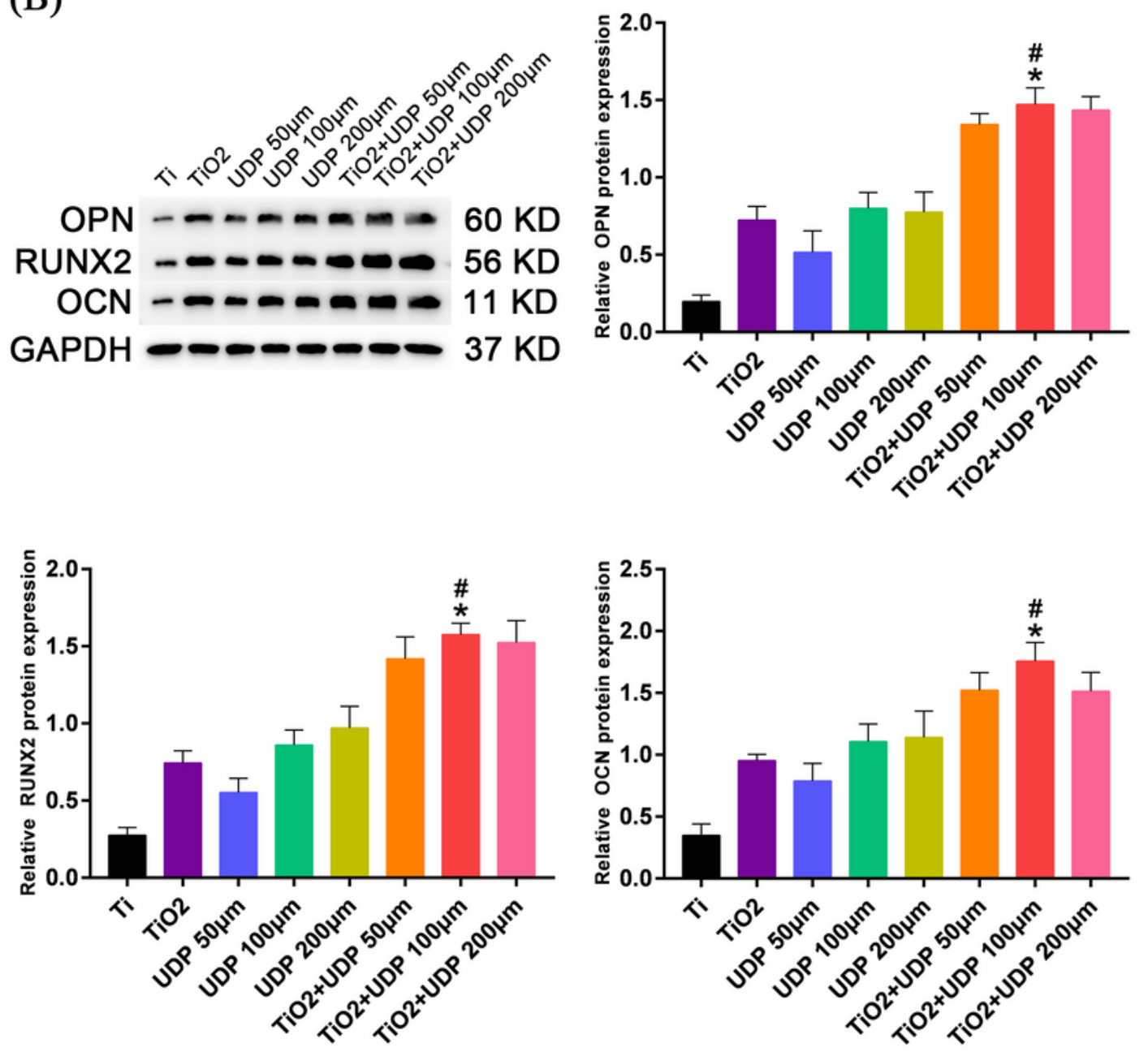

Figure 6

Effect of TiO2 nanotubes combined with P2Y6 agonists on osteogenic markers. (A) qRT-PCR and (B) western blot were used to analyze the effects of nanotubes and/or UDP on osteogenic induction of BMSCs. The mRNA and protein expression of osteogenic markers was normalized against GAPDH. Data represent means $\pm S D$ and statistically significant differences are indicated; $n=3$; $* P<0.05$ vs. TiO2 group; $\#$ P $<0.05$ vs. $100 \mu \mathrm{M}$ UDP group. 


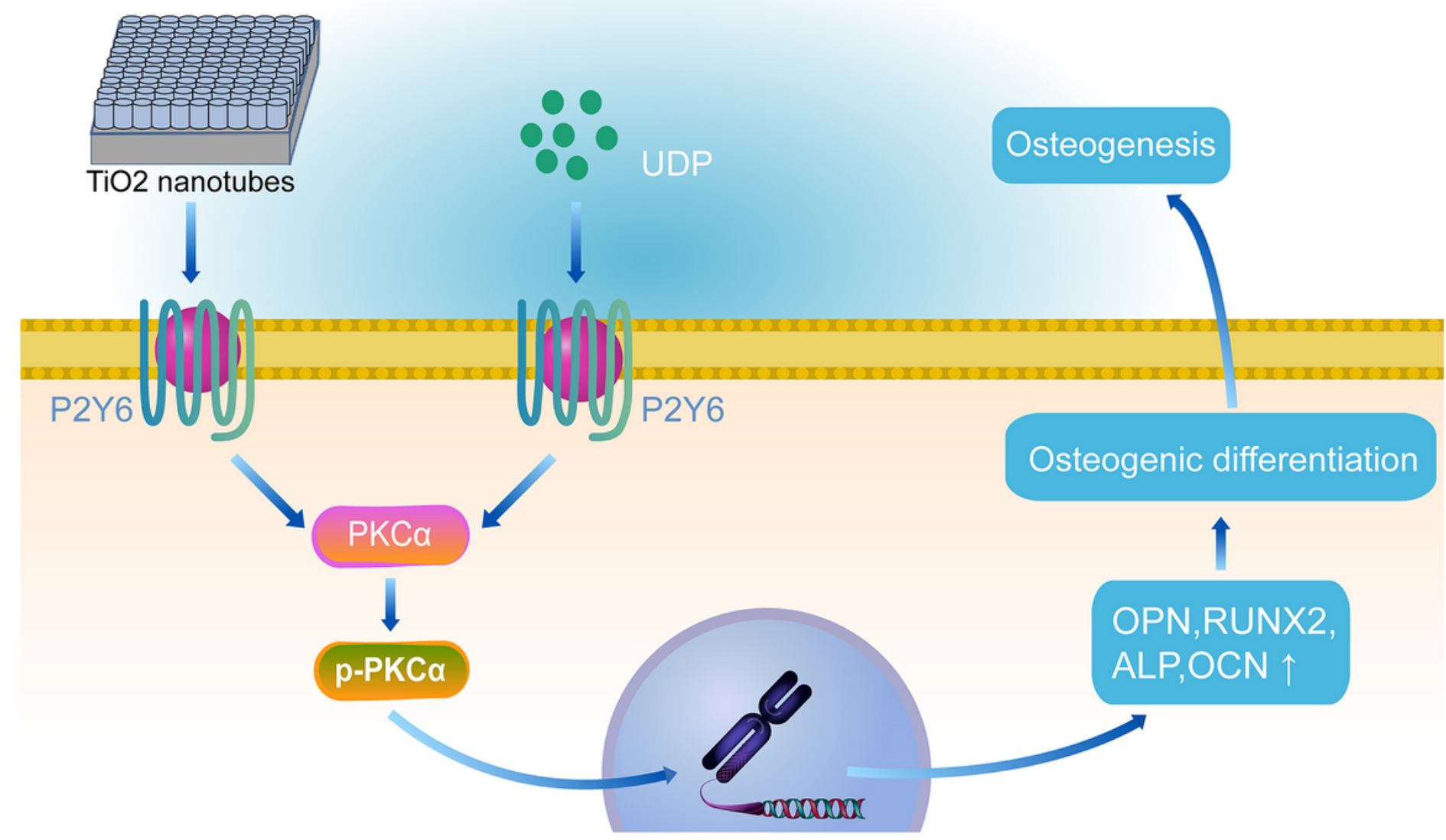

Figure 7

Schematic diagram of the upregulation of P2Y6 expression in BMSCs induced by $\mathrm{TiO} 2$ nanotubes and its downstream osteogenic effect. During the process of osteogenic differentiation, the expression of P2Y6 in BMSCs incubated with TiO2 nanotubes was upregulated. The upregulation of P2Y6 induced by TiO2 nanotubes can be activated by UDP. P2Y 6 activates the PKCa-ERK1/2 signaling pathway, upregulates the expression of osteogenic markers, and promotes the osteogenic differentiation of BMSCs. 